\title{
Vivências paternas durante a hospitalização do recém-nascido prematuro na Unidade de Terapia Intensiva Neonatal
}

\author{
Fathers' experiences during the hospitalization of the premature newborn in the Neonatal Intensive Care Unit \\ Experiencias paternas durante la hospitalización del recién nacido prematuro \\ en la Unidad de Cuidados Intensivos Neonatal
}

\begin{abstract}
Luciano Marques Santos', Cíntia Lorena de Souza Silva", Rosana Castelo Branco de Santana'"I, Vivane Euzébia Pereira Santos ${ }^{\text {IV }}$

'Universidade Federal do Vale do São Francisco, Curso de Graduação em Enfermagem, Grupo de Estudos e Pesquisas sobre Cuidado em Saúde (Líder). Feira de Santana-BA, Brasil.

"Faculdade de Tecnologia e Ciências, Curso de Graduação em Enfermagem, Grupo de Estudos e Pesquisas sobre Saúde da Mulher e da Criança. Feira de Santana-BA, Brasil.

I" Universidade Estadual de Feira de Santana, Curso de Graduação em Enfermagem (Graduanda). Feira de Santana-BA, Brasil.

Iv Universidade Federal do Vale do São Francisco, Curso de Graduação em Enfermagem, Núcleo de Estudos sobre Gênero e Atenção à Saúde da Mulher e Grupo de Estudos e Pesquisas sobre Cuidado em Saúde (Pesquisadora). Petrolina-PE, Brasil.
\end{abstract}

Submissão: 28-02-2011 Aprovação: 27-11-2012

\section{RESUMO}

Este estudo objetivou compreender as vivências paternas durante a hospitalização do recém-nascido prematuro na Unidade de Terapia Intensiva Neonatal de um hospital público de Feira de Santana, Bahia. Trata-se de um estudo descritivo, exploratório e qualitativo, aprovado por Comitê de Ética em Pesquisa e realizado com nove pais, na Unidade de Terapia Intensiva Neonatal de um hospital público. Os dados foram analisados através da Análise de Conteúdo, os quais apontaram que os partos prematuros causam sentimentos de surpresa, angústia e medo nos pais. É preciso repensar como ocorre a inserção dos pais do prematuro no processo de hospitalização, bem como mudanças nas rotinas estabelecidas para a visita e participação paterna no contexto do cuidado ao prematuro.

Descritores: Enfermagem Neonatal; Unidades de Terapia Intensiva Neonatal; Prematuro.

\section{ABSTRACT}

This study aimed to understand the fathers' experiences during the hospitalization of premature newborn in the Neonatal Intensive Care Unit at a public hospital in Feira de Santana, Bahia. This is a qualitative descriptive exploratory study that was approved by the Ethics Committee of the Faculty of Technology and Sciences, and carried out in a public hospital in Bahia, with nine fathers who accompanied their children hospitalized in the Neonatal Intensive Care Unit. The data were analyzed through content analysis. The results showed that premature births cause feelings of surprise, anxiety and fear in the fathers. It is needed rethink how does the inclusion of premature infants' fathers in the hospitalization process and about the changes in established routines for the visit and paternal participation in the context of premature care.

Key words: Neonatal Nursing; Intensive Therapy Units, Neonatal; Infant, Premature.

\section{RESUMEN}

Este estudio tuvo como objetivo comprender la experiencia de los padres durante la hospitalización de los bebés prematuros en la Unidad Neonatal de Cuidados Intensivos de un hospital público en Feira de Santana, Bahia. Se trata de un estudio descriptivo y cuantitativo, aprobado por el Comité de Ética en Investigación y actuó en la Unidad de Cuidados Intensivos Neonatales de un hospital público de Bahia, con nueve padres. Los datos fueron analizados utilizando el análisis de contenido que muestran que los nacimientos prematuros causan sentimientos de sorpresa en los padres, de dolor y de miedo. Tenemos que repensar cómo se está insertando a los padres de bebés prematuros en las cuestiones de la hospitalización y los cambios en las rutinas establecidas para la visita y la participación del padre en el contexto de la atención precoz.

Palabras clave: Enfermería Neonatal; Unidades de Cuidados Intensivos Neonatales; Prematuro.

Extraído do Trabalho de Conclusão do Curso "Percepção paterna sobre a hospitalização do recém-nascido prematuro na Unidade de Terapia Intensiva Neonatal", apresentado, em 2010, ao Curso de Graduação em Enfermagem da Faculdade de Tecnologia e Ciências. Feira de Santana-BA, Brasil.. 


\section{INTRODUÇÃO}

Em todo o mundo, segundo dados do Ministério da Saúde, nascem anualmente vinte milhões de crianças prematuras e com baixo peso, sendo que, dessas, um terço morre antes de completar um ano de vida. No Brasil, a primeira causa de mortalidade infantil são as afecções perinatais, mais comuns em crianças prematuras e de baixo peso ${ }^{(1)}$.

Dados da Organização Mundial de Saúde (2012) apontam que 15 milhões de neonatos nascem muito cedo todos os anos. Mais de 1 em cada 10 bebês nascem prematuros, afetando famílias em todo o mundo e mais de 1 milhão de crianças morrem a cada ano devido a complicações de parto prematuro. Muitos sobreviventes enfrentam uma vida inteira de deficiência, incluindo dificuldades de aprendizagem e visuais e problemas auditivos ${ }^{(2)}$.

São necessárias medidas urgentes para enfrentar este problema de saúde pública, especialmente porque as taxas de nascimentos prematuros estão aumentando a cada ano. Isto é essencial a fim de se obter progresso nos Objectivos para o Desenvolvimento do Milênio (ODM) para sobrevivência infantil até 2015 e mais além, uma vez que $40 \%$ das mortes em menores de cinco anos são em recém-nascidos. Para recém-nasccidos que sobrevivem, existe um risco aumentado de deficiência, que cobra uma pesada carga sobre as famílias e sistemas de saúde ${ }^{(2)}$.

Desta forma, nota-se que o nascimento prematuro é uma realidade mundial que vem demandando a articulação de estratégias para o seu enfrentamento, principalmente no que se refere à participação das famílias no contexto hospitalar. Diante disso, o país, atualmente, vem trabalhando com a visão de um novo paradigma, que é a da atenção humanizada à criança, e sua família no contexto da hospitalização ${ }^{(1)}$.

O grande número de nascimentos de recém-nascidos prematuros constitui-se em um problema de saúde pública, e ainda, pode provocar graves consequências tanto médicas quanto sociais. Além de ser um atendimento oneroso, manter o recém-nascido prematuro na incubadora aumenta as chances da desvinculação emocional no relacionamento com seus familiares.

Diante desta situação, destaca-se o Método Canguru, um novo modelo de cuidado que amplia as ações do espaço hospitalar para o núcleo familiar, com o intuito de humanizar a atenção ao prematuro e sua família. Esse modelo não anula ou substitui as condutas tradicionais e os tratamentos terapêuticos, isso porque todos os problemas de saúde necessitam de diagnóstico preciso e tratamento apropriado. Entretanto, vale salientar que este método coopera na recuperação gradativa da saúde e qualidade de vida do recém-nascido ${ }^{(3)}$.

O Método Canguru, no tocante à segurança física-biológica-emocional do recém-nascido prematuro, traz vantagens porque além de aumentar o vínculo entre mãe e filho, favorece a produção do leite materno, que beneficia a lactação e a amamentação. Tal método também ajuda no desenvolvimento físico-emocional da criança estimulando os laços afetivos. Este modelo de cuidado ajuda a diminuir tanto o estresse como o choro do recém-nascido, favorecendo a estabilidade emocional da criança, fator preponderante na sua recuperação clínica(4).
Por isso, apesar das vantagens citadas, a atenção ao recém-nascido têm se limitado à inserção de ações pontuais relacionadas à genitora, sendo excluídas deste processo, a participação e as necessidades paternas. Por outro lado, o atual panorama da produção do conhecimento em Enfermagem Neonatal, reforça a cultura e histórica divisão social de papéis entre homens e mulheres, já que os estudos focalizam em sua maioria a participação materna no cuidado ao prematuro, tanto no âmbito hospitalar, quanto doméstico.

Assim, é preciso incorporar na prática clínica a visão ampliada de família como um sistema complexo em mútua interação, que demanda a articulação de estratégias por parte dos profissionais de saúde, já que a experiência da doença e hospitalização de um de seus membros afeta a sua integridade e funcionamento como um todo.

Desta forma, este estudo teve como objeto de investigação as vivências paternas durante a hospitalização do recém-nascido prematuro na Unidade de Terapia Intensiva Neonatal (UTIN).

$\mathrm{O}$ interesse por este objeto surgiu durante a graduação em enfermagem ao observar que na Unidade de Terapia Intensiva Neonatal da maternidade onde este estudo foi realizado, havia exclusivamente a participação materna. Notou-se uma facilidade de acesso materno ao espaço da unidade neonatal. Assim, as mães possuíam liberdade nos horários de visitas ao recém-nascido prematuro, mas ao pai eram designados horários restritos. Diante de tais observações no campo de estágio surgiram várias questões: Porque somente as mães recebiam tratamento especial? Porque as visitas dos pais e demais familiares eram restritas? Porque o pai não estava inserido no cuidado?

A equipe de enfermagem elaborava normas e rotinas institucionais que impediam os pais do recém-nascido prematuro de visitá-los depois das dezoito horas. Esta rotina era justificada pelo argumento de que era uma norma da instituição e que ficava perigoso deixar homens circulando pelo corredor central da unidade hospitalar. Isto posto, questionou-se: como os pais vivenciam a hospitalização do recém-nascido prematuro na Unidade de Terapia Intensiva Neonatal?

Tendo em vista estes aspectos, este estudo teve como objetivo compreender as vivências paternas durante a hospitalização do recém-nascido prematuro na Unidade de Terapia Intensiva Neonatal de um hospital público de Feira de Santana-BA.

\section{METODOLOGIA}

Este estudo foi de natureza descritiva, exploratória e qualitativa. O estudo foi realizado em uma cidade do estado da Bahia, pelas suas características sócio-econômicas e importância geográfica. O hospital especializado na atenção à mulher no ciclo gravídico e puerperal desta cidade foi o campo empírico deste estudo. Esta é uma instituição pública de médio porte da esfera municipal, configurando-se numa fundação hospitalar. O hospital atende mulheres procedentes de todo o município e regiões circunvizinhas. Presta atendimento hospitalar à mulher durante e trabalho de parto, parto e puerpério e ao recém-nascido em condições normais ou com diversas patologias. 
Participaram do estudo nove pais que acompanhavam seus filhos internados na Unidade de Terapia Intensiva Neonatal do referido hospital, mediante assinatura do Termo de Consentimento Livre Esclarecido.

Para a escolha dos participantes, utilizaram-se os seguintes critérios de inclusão: ser pai de recém-nascido sem malformações congênitas; ser pai pela primeira vez; ser pai de recém-nascido prematuro com mais de sete dias de internação na UTIN; visitar o recém-nascido prematuro semanalmente; desejar participar do estudo e aceitar assinar o Termo de Consentimento Livre e Esclarecido.

Os dados foram coletados no período de fevereiro a abril de 2010, após a aprovação do Comitê de Ética na Pesquisa. Para a apreensão do material empírico, foi utilizada a técnica da entrevista, acreditando-se ser a melhor forma para atingir os objetivos propostos na pesquisa. Dentre as formas existentes para se realizar a entrevista, utilizou-se a entrevista semi-estruturada que combina perguntas fechadas (ou estruturadas) e abertas, onde o entrevistado tem a possibilidade de discorrer sobre o tema proposto, sem respostas ou condições prefixadas pelo pesquisador ${ }^{(5)}$.

Utilizou-se um roteiro de entrevista para a coleta de dados com questões de identificação pessoais e as seguintes questões norteadoras: Como está sendo para o senhor ter um filho hospitalizado na Unidade de Terapia Intensiva Neonatal? Conte para mim como o senhor se sentiu ao saber que seu filho seria hospitalizado nesta Unidade de Terapia Intensiva Neonatal.

Para a análise dos dados empíricos utilizou-se a Análise de Conteúdo que diz respeito à descoberta do que está por trás dos conteúdos manifestos, indo além das aparências do que está sendo comunicado ${ }^{(6)}$. A Análise de Conteúdo é um conjunto de técnicas de análise das comunicações, que pode expresar uma análise de significados (a análise temática), como também uma análise dos significantes (análise léxica, análise dos procedimentos $)^{(7)}$.

Assim, após a realização de cada uma, as falas dos participantes foram transcritas na íntegra. No primeiro contato com o material empírico, realizou-se uma leitura superficial, com vistas a aproximação com o contéudo latente de cada fala, seguida de leituras exaustivas do material, com intuito de indentificação das unidades de análise, das unidades de significação e construção das seguintes categorias: Um evento inesperado; Sentimentos vivenciados e Um novo pai.

O estudo respeitou a Resolução no 196/96, do Conselho Nacional de Saúde, sendo emitido parecer favorável pelo Comitê de Ética na Pesquisa da Faculdade de Tecnologia e Ciências, campus de Salvador-BA, através do Parecer n 1.664-2009.

Os princípios éticos foram contemplados no desenvolvimento deste estudo para proteger os direitos dos colaboradores durante o processo de coleta dos dados. Para tanto, todos os participantes deste estudo receberam informações sobre o mesmo e assinaram o Termo de Consentimento Livre e Esclarecido.

Por razões éticas os pais não foram identificados pelos seus nomes, sendo assegurado o anonimato dos entrevistados, através da utilização de códigos na transcrição e divulgação da sua fala. Dessa forma, os participantes da pesquisa foram tratados em sua dignidade, respeitando sua autonomia e sendo identificados por códigos, a saber, E01, E02, E03, E04, E05, E06, E07, E08 e E09.

\section{RESULTADOS}

\section{A. Um evento inesperado}

Os pais vivenciam a notícia de um parto prematuro e a necessidade de hospitalização do filho na Unidade de Terapia Intensiva Neonatal como um momento de surpresa e de preocupação. Para eles, a interrupção do processo gestacional antes da data prevista para o parto, ocorreu de forma abrupta e inesperada para a família, conforme falas a seguir:

[...] Um pouco preocupante, entendeu? No sentido que a gente espera uma criança de nove meses e foi de sete [...] De primeira viagem a gente não imagina tanta coisa assim, foi um choque, tiveram que fazer o parto nas pressas. (E02)

[...] isso aí foi de uma hora pra outra que aconteceu, de uma hora pra outra. (E05)

[...] meu primeiro filho, tudo aconteceu tão rápido. Está sendo uma barreira vê-lo na UTI. (E06)

[...] Senti que foi uma surpresa, eu acho que nunca imaginava, né? isso ai me pegou de surpresa. (E07)

[...] Bom, no início, a gente não tinha idéia, nem eu, nem minha mulher. Porque ela veio para aqui, deu uma dor e veio para aqui e a gente não achava que era uma coisa tão grave, mas foi uma coisa assim, de repente, precisou fazer a cesárea. (E03)

\section{B. Sentimentos vivenciados}

A percepção acerca da UTIN, de que este é um espaço hospitalar bastante perigoso, devido ao risco iminente de morte do recém-nascido hospitalizado, contribui para a vivência da ansiedade, angústia e insegurança por parte dos pais. Para eles, a notícia da necessidade de internação do filho na referida unidade foi uma vivência difícil e estressante, em decorrência da fragilidade decorrente da prematuridade do filho.

[...] Minha sogra disse que o bebê ia precisar ir pra uma UTIN, que era um berçário de alto risco, pra um lugar mais perigoso. No momento, eu fiquei chocado com aquilo, aí o bebê foi, mas o médico avaliou e disse que não precisava ele ficar ali na UTIN. (EO4)

[...] quando eu soube que meu filho estava na UTIN, me senti muito mal, muito triste, rapaz nem sei descrever, mas foi duro, muito, muito, muito duro, foi duro de aceitar, mas são coisas da vida, né? Tem que aceitar querendo ou não. (E05)

[...] No caso de uma criança recém-nascida, ela vem fraca, vem sem [...] prematura, tudo em formação ainda. Foi um susto saber que meu filho ia qualquer momento tá na UTI. (E09) 
Ao visitar o filho pela primeira vez na UTIN, os pais relataram que diante do estado de saúde do recém-nascido e dos equipamentos utilizados por ele, apresentaram diversos sentimentos, tais como impotência, tristeza, solidão, angústia e medo.

[...] era tão pequenininho, parecia tão fraco que eu tinha medo de pegar no colo, assim como fiz quando meu primeiro filho nasceu. (E01)

[...] eu senti um aperto no coração, né? Nesse momento, a gente fica sem chão, a gente perde a estabilidade, então, pra mim, foi uma a coisa mais dolorosa [...] eu nunca tinha passado por isso. (E02)

[...] no momento da primeira visita a gente toma um susto, entendeu?é muito aparelho ligado na criança. (EO3)

[...] senti que foi uma surpresa, eu acho que nunca imaginava, né? Nisso ai me pegou de surpresa [..]. chorei muito, fiquei triste, sozinho [...] ele não conseguia respirar sozinho, era muito pequeno, tive medo de tocar nele, eu nunca tinha um bebê nascido fora tempo, não sabia que colocava tanto fio, tanto aparelho. (E07)

[...] eu vi que ele estava na UTI, eu me senti um inútil, sem poder fazer nada porque é muito difícil a pessoa ter um filho assim e passar por uma coisa dessa eu preferia tá no lugar dele hoje do que ele tá ali.(E08)

Para os pais entrevistados, com o passar dos dias de hospitalização do prematuro na UTIN, os sentimentos vão sendo intensificados, pois o prematuro é um ser frágil e o risco de morte é eminente.

Para eles, o medo, a tristeza, a angústia e a impotência são acentuadas pela percepção de que o filho não poderá ir para casa tão cedo, mediante suas condições clínicas, o que provoca a sensação de vazio no domicílio e o choro intenso. Nesta vivência, os pais informaram que se sentiram desesperados, sozinhos e diariamente tristes, pelo fato de não possuir recursos para ajudar o filho hospitalizado, conforme observado nas seguintes falas:

[...] Não tenho nem palavras pra explicar [..]. sinto bastante tristeza, porque ele não está em casa com a família, sinto falta. (E06)

[...] eu me senti muito mal, muito triste, chorei muito [...] muito difícil, porque ele está aqui no hospital e não está na minha casa. (E01)

[...] a sensação é de desespero, tristeza [..]. não dá nem vontade de ficar em casa é só tristeza saber que tem um bebê ali tão pequeno sofrendo, a gente chora, fica num cantinho ali, aí não tem como segurar não. (EO4)

[...] sinto bastante tristeza dele não estar em casa com família, sinto falta. (E05)
[...] chorei muito, fiquei triste, sozinho, isso aí foi de uma hora pra outra que aconteceu [...] eu estou sentindo que não estou muito satisfeito porque que ele está ali queria que estivesse tudo em dias, tudo ok. (E07)

\section{Um novo pai}

A doença e a hospitalização de um membro afetam o restante da família provocando a expressão de diversos sentimentos. Por isso, os entrevistados, referiram sofrer juntamente com a esposa que acompanha o prematuro na UTIN, sendo este representado pelos episódios de choro e a necessidade de obter informações sobre a verdadeira condição de saúde filho. Isso reforça o desejo do pai de estar mais próximo da situação e elaborar estratégias para o seu enfrentamento.

[...] quando vejo minha mulher chorando, vou num cantinho e choro também, sei que ela sofre. (E04)

[...] Eu gostaria de saber o que realmente pode acontecer, de uma hora pra outra as coisas podem mudar [...] eu mesmo, já começo a me preparar para o que possa acontecer. (E05)

Entretanto, foi identificado em uma das entrevistas que a preocupação com a situação clínica do prematuro seria uma obrigação materna e não do pai.

[...] no meu jeito de pensar, estou aceitando tranquilamente estou só esperando a resposta, o desenvolver dela que acho que está sendo bom. Mas em relação a preocupação eu creio que não, isso vai mais por parte da mãe do que do próprio pai, o pai é mais na dele. (E09)

A situação de internamento do filho, muitas vezes dá a sensação de impotência para os pais, geralmente, se sente culpado por pensar que não está cumprindo seu papel de protetor e defensor do filho, daí surge o desejo de transferência, de tomar para si a aquilo que o filho vive, como identificado nestas falas seguintes:

[...] eu preferia tá no lugar dele hoje, do que ele tá ali.(E08)

\section{[...] queria ta lá com ela, no lugar dela. (E03)}

Ainda, a ideia de que o homem tem o papel de provedor da família, com a função de providenciar o seu sustento e suprir suas necessidades básicas, pode ser encarado pelo homem como uma obrigação, não sendo permitido falhar neste ponto. Desta forma, durante a hospitalização do filho na UTIN, o pai vivencia uma situação de estresse intenso, pois teme perder seu emprego por faltas, atrasos ou licenças, e vê na continuação de suas atividades a segurança financeira que precisa proporcionar à família.

Mas ao mesmo tempo em que tenta cumprir seu papel ele se sente culpado por não passar mais tempo com seu filho hospitalizado.

[...] tenho que trabalhar [...] mas eu queria estar mais aqui 
com ele, mas não posso estar aqui todo dia, moro em outra cidade e tenho outros filhos também. (E04)

\section{DISCUSSÃO}

A experiência de ter um filho inaugura um momento importante no ciclo vital da mulher e do homem, com grandes repercussões no meio familiar ${ }^{(1)}$. Assim, o parto prematuro significa interromper com o sonho de ter o filho em tempo normal, livre de intercorrências uma vez que interfere no curso do processo gravídico e desencadeia a hospitalização do recém-nascido em cuidados intensivos ${ }^{(8-9)}$.

A hospitalização do recém-nascido na UTIN, por si só, é um evento atribulador, que provoca estresse e insegurança nos familiares devido à condição de vulnerabilidade de sua saúde. O enfrentamento dessa situação é mais difícil quando a internação é necessária logo após o nascimento, substituindo a idealização da chegada de um bebê saudável pelo enfrentamento das adversidades e dos sentimentos provocados pela hospitalização ${ }^{(10)}$.

Por isso, o parto prematuro é considerado um evento inesperado na vida dos pais, já que o mesmo ocorre de uma forma não planejada, impactando na família, por meio de mudanças na dinâmica e rotina familiar, gerando novas demandas e papéis sociais que precisam ser reconhecidos pelos trabalhadores da saúde.

O pai, da mesma forma que a mãe acompanhante do prematuro na UTIN, precisa se adaptar de maneira repentina à nova situação vivenciada diante do nascimento prematuro, sendo esta uma experiência nova e com intenso sofrimento para ele, já que vivencia a imprevisibilidade da situação clínica do filho hospitalizado.

Desta forma, o nascimento de um recém-nascido em condição de risco e a necessidade de internação em cuidados intensivos, pode trazer aos pais sentimentos de insegurança e incerteza quanto à vida e ao prognóstico deste filho. Depois do nascimento, o momento que antecipa a primeira visita ao recém-nascido é mistificado pela imagem popular acerca da UTIN como um ambiente complexo, destinado a pacientes graves e com poucas expectativas de vida $^{(10)}$, pois a ideia que permeia o imaginário popular sobre a UTIN é de um ambiente inóspito, frio, silencioso e para onde são levados os pacientes em estado grave que, geralmente ficam conectados a tubos e aparelhos, onde só é permitida a entrada de funcionários e membros da família em horários pré-definidos.

Por isso, a internação na UTIN está relacionada à dor da separação, uma associação quase imediata com a ideia de finitude e ao sentimento de morte. Esta unidade é uma unidade de alta complexidade, onde o viver e o morrer estão mais presentes na imaginação das famílias. Sendo um setor no qual o paciente é admitido em estado crítico de saúde, passa a representar para os pais algo adverso ao esperado durante a gravidez $^{(10-11)}$.

A falta de informação e de conhecimento prévio em relação à UTIN e a incerteza quanto ao verdadeiro estado de saúde do recém-nascido são aspectos que geram insegurança e medo nos pais. Destra maneira, os familiares desconhecem esta unidade de cuidados complexos e suas rotinas considerando-o como ambiente assustador ${ }^{(12)}$

Os pais vivenciam sentimentos diversos ao visitar o filho prematuro como a impotência, a tristeza, a solidão e a dor. Tais sentimentos podem estar associados às características da própria UTIN, sua dinâmica de funcionamento e dispositivos de apoio à vida, utilizados para garantir e manter a sobrevida do prematuro.

A UTIN é um cenário familiar para os profissionais de saúde que ali atuam, porém, para os pais, pode parecer um ambiente hostil e pouco acolhedor desencadeando sentimentos e reações desagradáveis como tristeza, ansiedade, angústia e principalmente medo. Esta unidade pode ser traumatizante, pois na maioria das vezes a admissão do paciente ocorre de forma não planejada gerando nos familiares oscilações psicológicas expressas por diversas emoções, por sentirem-se impotentes diante da situação vivenciada ${ }^{(11)}$.

Outrossim, dentro da ordem familiar, a figura paterna é muitas vezes, por questões históricas e sociais, vista como a de provedor do sustento, e mantenedor da família. Neste contexto, o pai é considerado como protetor e responsável pela resolução dos problemas de sua família. O pai, porém, ante o fato de não poder resolver o problema de seu filho e acompanhá-lo durante seu momento de fragilidade que é a internação em cuidados intensivos, sente-se impotente ${ }^{(13)}$.

A internação do prematuro na UTIN é uma situação de crise para toda a família, pois esse é um ambiente ao mesmo tempo, estranho e assustador. Para agravar essa situação, cabe citar que o bebê real é distante daquele imaginado pelos pais e o sentimento de culpa pelos problemas do filho atua como fator que inibe o contato natural entre pais e filhos prematuros. Ao entrar na UTIN pela primeira vez, o pai experimenta a perplexidade e o medo em face de uma realidade diferente da que foi idealizada com a chegada do seu filho ${ }^{(14)}$.

É comum a família se assustar ao ver o recém-nascido conectado a tubos e a aparelhos, imersos na estranheza do mundo do cuidado intensivo neonatal. A visão de um bebê extremamente doente, cercado de cuidados e aparelhos, pode ser muito dolorosa para os pais e certamente influenciará na qualidade do contato inicial. Assim, o medo da perda iminente e do desconhecido transformará, provavelmente, um momento de alegria em dúvidas e incertezas sobre o futuro próximo ${ }^{(13)}$.

A tristeza ganha um sentido bem mais amplo para os pais e está correlacionada com a preocupação do fato de seu filho ficar internado, evidenciando-se a frustração do pai em não levá-lo para casa, como esperado nos nove meses de gestação ${ }^{(13)}$. Os sentimentos dos pais relacionados ao bebê real, prematuro, compreendem fracasso, orgulho ferido, irrealidade, culpa, aparência física decepcionante, bebê incompleto e sensação de vazio ${ }^{(15)}$.

Entretanto, mediante a inserção do pai no contexto do cuidado intensivo neonatal, nota-se uma nova figura paterna, que se preocupa com a manutenção da integridade e unidade familiar. Este novo pai além de vivenciar novos sentimentos, experimenta a dor, a amargura e o receio ao deparar-se com o filho na UTIN e com a sensação de não saber se irá conseguir lidar com toda essa situação. 
Este novo pai acredita participar ativamente da gestação de sua esposa, através do apoio emocional ou material. O novo pai está mais disponível para ouvir sua esposa, procurando compreender seus medos e angústias. Além disso, procuram informar-se, através de leituras e troca de experiências com outros pais, sobre assuntos relacionados à gestação e cuidados com o filho. O apoio material é representado pela realização de tarefas para a esposa, sendo esta uma forma de expressar seu interesse pelo recém-nascido e agradar sua esposa(16).

Enfrentar esta experiência põe em questão emoções e sentimentos que se confrontam com a postura que o pai assume perante a família e a sociedade. Esse pai anseia dar continuidade ao cuidado do filho prematuro, tentando harmonizar aquilo que sente com aquilo que pensa e tem que fazer. Este novo pai possui expectativas em relação ao papel paterno, de ser um pai participativo e presente na vida do filho.

Estes pais, devido ao trabalho, não conseguem permanecer o tempo que gostariam com seus filhos. A participação se resume, então, ao tempo que estes estão disponíveis e não à integralidade de tempo em que a criança precisa de cuidados. O "ser pai" tem abrigado uma coexistência entre modelos provenientes dos sistemas patriarcal, moderno e pós-moderno, mistura que torna ainda mais singular a experiência de cada homem. Mesmo convivendo com estes modelos históricos, percebe-se que há um esforço dos pais em envolver-se afetivamente com os filhos, demonstrando o amor e carinho que sentem, sem rechaçar os seus sentimentos ou valores associados à sua "masculinidade"(17).

Diante do exposto, é possível notar que surge uma nova configuração paterna, onde o pai não é mais visto como coadjuvante do processo de hospitalização do prematuro na UTIN e provedor da família. Este novo pai passa a ter um papel fundamental, assim como o da figura materna, pois faz parte de um sistema maior que precisa ser inserido como unidade de cuidado nos estabelecimentos de saúde, e que se preocupa com a situação de sua esposa e do filho hospitalizado, rompendo com a cristalizada imagem de um ser que não pode expressar sentimentos diante de uma sociedade que o afasta das ações de cuidado para com a sua prole.

Sendo assim, percebe-se a necessidade de os profissionais de enfermagem aliarem a técnica e cuidado humanitário ao conhecimento, oferecendo cuidado integral à família inserida no contexto do cuidado intensivo neonatal ${ }^{(18)}$. Compreender a experiência de ser pai de um recém-nascido prematuro internado na UTIN, não é uma tarefa simples, mas necessária ao profissional que exerce sua prática junto a esta clientela, sendo imprescindível a valorizar a comunicação, o relacionamento humano e olhar atento sobre a forma como os mesmos vivenciam a paternidade desde o início da gestação ${ }^{(14,19)}$.

Os serviços de saúde devem ampliar o foco de observação e de cuidados para além da dupla mãe-lactente, promovendo condições para participação do pai nos diversos contextos do cuidado neonatal e pediátrico, e assim prevenir seu distanciamento do exercício do papel de pai, em consonância com as modificações no contexto familiar contemporâneo ${ }^{(20)}$.

Por isso, ao vivenciar o processo de hospitalização do filho na UTIN, o pai terá a oportunidade de expressar sentimentos remodelando o papel socialmente designado para ele, inserindo-se como corresponsável no cuidado ao prematuro. Ainda, a inserção da figura paterna no cuidado intensivo neonatal precisa ser considerada como a extensão da atenção oferecida ao prematuro, ampliando a visão dos profissionais de saúde para o Cuidado Centrado na Família.

\section{CONSIDERAÇÕES FINAIS}

Os resultados denotaram que ter um filho internado na UTIN é um evento visto como assustador e uma surpresa na vida dos pais estudados, desencadeando sentimentos de tristeza, angústia, dor e impotência. Além disso, foi percebido que o ambiente desta unidade é desconhecido e estigmatizado por ser tido como um lugar para morrer.

Os sentimentos dos pais são semelhantes aos das mães diante da hospitalização de seus filhos prematuros, sendo o período de internamento um dos mais turbulentos de sua vida, pois além das dificuldades diárias, o pai ainda tem de conviver com a incerteza sobre o futuro do seu filho prematuro.

As informações obtidas sugerem que mesmo diante de difícil situação, o pai deseja ser inserido no processo de hospitalização do filho, entretanto, muitos deles não conseguem acompanhar de perto sua evolução por vários motivos, como fatores financeiros, horários restritos de visitas, dentre outros.

Nesse estudo, a notícia da internação do recém-nascido prematuro na UTIN proporcionou a vivência de sentimentos diversos, associados, geralmente, ao medo e imprevisibilidade da morte do filho prematuro. Nessa perspectiva, acredita-se que a imagem desta como um lugar sombrio, somente poderá ser superada quando as pessoas tiverem informações claras e precisas sobre esta unidade, sua dinâmica de funcionamento, pacientes que são indicados para o cuidado neste setor e quais são os procedimentos realizados diariamente.

Percebeu-se que os pais participam do processo de hospitalização do prematuro como um coadjuvante deste processo, sendo necessária sua inserção no cuidado ao recém-nascido prematuro, entretanto não exclusivamente com um visitante diário, mas como uma constante na vida do filho, que demanda atenção. Os pais poderiam participar de alguns cuidados tais como o banho, a amamentação ou troca de fraldas, como ocorre com a genitora.

Para a melhoria da participação paterna na UTIN sugere-se que a sua entrada nessas unidades deva ser livre, sem limites, e visualizada como um direito do mesmo e não como uma permissão concedida pela equipe de saúde ou visitante. É preciso transferir para a prática as evidências do conhecimento relacionadas ao sofrimento da família que vivencia a hospitalização do prematuro na UTIN e as estratégias utilizadas para amenizar o impacto decorrente deste processo.

Assim, sugere-se a inclusão dos demais membros da família no contexto do cuidado intensivo neonatal, para que desta forma a filosofia do Cuidado Centrado na Família possa ser uma realidade da prática, transpondo o campo teórico.

Por isso, a realização deste estudo foi relevante, pois os dados empíricos poderão auxiliar os profissionais de saúde a repensar a forma como está sendo a participação paterna 
durante a hospitalização do prematuro em cuidados intensivos, bem como apontar mudanças em longo prazo na relação aí estabelecida entre profissionais e a figura paterna.

Ainda, os dados empíricos poderão estimular a realização de novas investigações, tendo em vista a reduzida produção do conhecimento relativa ao objeto investigado. Outro ponto a ser investigado é a questão do gênero que poderá ser discutida pelos profissionais envolvidos no cuidado ao neonato prematuro com vista à reformulação das rotinas estabelecidas para a visita e participação paterna no contexto da UTIN, no sentido de valorizar o potencial desta nova figura no cuidado ao prematuro.

\section{REFERÊNCIAS}

1. Ministério da Saúde, Secretaria de Políticas de Saúde, Área de Saúde da Criança. Atenção humanizada ao recém-nascido de baixo peso: Método Canguru. Brasília: Ministério da Saúde; 2009.

2. World Health Organization. Born too soon: the global action report on preterm birth. WHO: Geneva; 2012.

3. Chapark, N, Figueroa CZ. O método mãe-canguru: pais e familiares de bebês prematuros podem substituir as incubadoras. Rio de Janeiro: MCGRAW-Hill; 1999.

4. Freitas JO. Método Mãe Canguru: evolução ponderal de recém-nascidos. Salvador. Dissertação [Mestrado em Enfermagem]- Universidade Federal da Bahia. Programa de Pós- Graduação em Enfermagem; 2005.

5. Minayo MCS. O desafio do conhecimento: pesquisa qualitativa em saúde. 6. ed. Rio de Janeiro: HUCITEC; 1999.

6. Minayo MCS. Pesquisa Social: teoria, método e criatividade. 4. ed. Petrópolis: vozes; 1995.

7. Bardin L. Análise de Conteúdo. Lisboa: Edições 70; 2007.

8. Tronchin DMR, Tsunechiro MA. O cuidar e o conviver com o filho prematuro: a experiência do pai. Rev Latino-Am Enferm 2006;14(1):93-101.

9. Tronchin DMR, Tsunechiro MA. A experiência de tornarem-se pais de prematuro: um enfoque etnográfico. Rev Bras Enferm 2005;58(1):49-54.

10. Schmidt KT, Sassá AH, Veronez M, Higarashi IH, Marcon SS. A primeira visita ao filho internado na unidade de terapia intensiva neonatal: percepção dos pais. Esc Anna Nery Rev Enferm 2012; 16(1):73-81.

11. Carvalho JBL, Araújo ACPF, Costa IC, Brito RS, Souza NL. Representação social de pais sobre o filho prematuro na unidade de terapia intensiva neonatal. Rev Bras Enferm 2009;62(5):734-8.

12. Lemos RCA, Rossi LA. O significado cultural atribuído ao centro de terapia intensiva por clientes e seus familiares: um elo entre a beira do abismo e a liberdade. Rev Latino-Am Enferm 2002;10(3):345-57.

13. Cardoso MVLML, Souto KS, Oliveira MMC. Compreendendo a experiência de ser pai de recém-nascido prematuro internado na unidade neonatal. Rev RENE 2006;7(3):49-55.

14. Fontoura FC, Fontenele FC, Cardoso MVLML, Sherlock MSM. Experiência de ser pai de recém-nascido prematuro internado em Unidade de Terapia Intensiva Neonatal. Rev RENE 2011; 12(3):518-25.

15. Santos MCL, Moraes GA, Vasconcelos MGL, Araújo EC. Sentimentos de pais diante do nascimento de um recém-nascido prematuro. Rev. Enferm. UFPE [periódico na internet]. 2007 [acesso em 18 out 2010]; 1(2):111-20 Disponível em: <http://www.ufpe.br/revistaenfermagem/ index.php/revista/article/view/374-8796-1 > .

16. Krob AD, Piccinini CA, Silva MR. A transição para a paternidade: da gestação ao segundo mês de vida do bebê. Psicol. USP [periódico na internet]. 2009 [acesso em 24 out 2012];20(2): 269-91 disponível em: <http:// www.revistasusp.sibi.usp.br/scielo.php?script $=$ sci $\mathrm{pdf} \& \mathrm{pid}=\mathrm{S} 1678-51772009000200008 \& \operatorname{lng}=\mathrm{pt} \& \mathrm{nrm}=\overline{\mathrm{i}}$ so\&tlng $=\mathrm{pt}>$.

17. Gabriel MR, Dias ACG. Percepções sobre a paternidade: descrevendo a si mesmo e o próprio pai como pai. Estud Psicol 2011;16(3):253-61.

18. Centa ML, Moreira EC, Pinto MNGHR. A experiência vivida pelas famílias de crianças hospitalizadas em uma unidade de terapia intensiva neonatal. Texto \& Contexto Enferm 2004;13(3):444-51.

19. Piccinini CA, Levandowski DC, Gomes AG, Lindenmeyer D, Lopes RS. Expectativas e sentimentos de pais em relação ao bebê durante a gestação. Estud psicol 2009;26(3):373-82.

20. Falceto OG, Fernandes CL, Baratojo C, Giugliani ERJ. Fatores associados ao envolvimento do pai nos cuidados do lactente. Rev Saúde Pública 2008;42(6):1034-40. 